\title{
Participação como foco de aprendizagem na educação permanente no Sistema Único de Assistência Social*
}

\author{
Participation as a learning focus in permanent education in the Single System of Social
}

Assistance

\author{
Stela Ferreira** \\ Abigail Torres ${ }^{* * *}$
}

\section{Resumo:}

O artigo sistematiza experiências de pesquisa, ensino e intervenção das autoras em processos de educação permanente com trabalhadores do Sistema Único de Assistência Social. Apresenta referências teóricas e éticas da pedagogia da problematização como método ativo de reflexão dos trabalhadores nos processos de educação permanente. Recupera a trajetória histórica da participação como diretriz das políticas sociais pós Constituição de 1988. Analisa limites dos espaços institucionalizados de participação. Contextualiza o desafio da participação como método e resultado do trabalho social. Apresenta gradientes de participação como analisadores da participação nos serviços para oferecer possibilidade de reflexão e aprimoramento das práticas profissionais na assistência social.

Palavras-Chave: Assistência social. Participação. Educação permanente.

\begin{abstract}
:
This article organizes and presents experiences of research, teaching and intervention of the authors in processes of permanent education with social service workers. It presents theoretical and ethical references of problem based learning (PBL) as an active method of workers reflections within the processes of permanent education. It recovers the historical trajectory of participation as social policy guideline afterwards the Constitution of 1988. It analyses the boundaries of institutionalized spaces of participation. It contextualizes the challenge of participation as method and outcomes of social work. It presents gradation of participation as index of participation in social work in order to offer ways of thoughts and improvement of social work practices.
\end{abstract}

Keywords: Social assistance. Participation. Permanent education.

\footnotetext{
* Artigo publicado nos Anais do III Seminário Nacional de Território e Gestão de Políticas Sociais. Universidade Estadual de Londrina, Jul. 2017.

** Doutora em Serviço Social pela PUC-SP. Docente do Centro Universitário Salesiano de São Paulo e pesquisadora do Programa das Nações Unidas para o Desenvolvimento (PNUD). E-mail: stelasferreira@gmail.com

*** Doutora em Serviço Social pela PUC-SP. Docente do Centro Universitário Salesiano de São Paulo e pesquisadora do Programa das Nações Unidas para o Desenvolvimento (PNUD). E-mail: abigailstorres@gmail.com
} 


\section{Nexos entre Democracia e Processos e Educação Permanente no Sistema Único de Assistência Social (SUAS)}

As reflexões contidas nesse artigo são resultado de um trabalho implicado que temos realizado como educadoras em processos de educação permanente ofertados por municípios e pelo governo federal, assim como pesquisadoras da temática do controle social e da educação permanente no Sistema Único de Assistência Social (SUAS). Trata-se, portanto, da sistematização de conteúdos advindos dos estudos especializados sobre participação social em políticas públicas; de diálogos sobre os desafios cotidianos enunciados por trabalhadores do SUAS nos processos de educação permanente e da produção de materiais instrucionais que criamos para apoiar as equipes no enfrentamento das dificuldades de fomento à participação dos usuários nos serviços da Assistência Social. Sistematização que significa, segundo o referencial da educação popular, organizar os registros para obter aprendizagens críticas a partir das nossas experiências.

Dessa perspectiva, concebemos o conhecimento científico como prática social que compõe, ao lado de outras práticas sociais, o processo de construção das instituições. Como tal, também precisa ser posto em análise, uma vez que frequentemente o conhecimento científico identifica-se com o "discurso competente" analisado por Chauí (1982, p. 58-59):

O discurso e a prática científicos, enquanto competentes, possuem regras precisas de exclusão e inclusão cuja determinação, em última circunstância, é dada finalmente, pela divisão das classes sociais. No entanto, não é apenas como reprodutora da divisão social e dos sistemas de exclusão social que a ciência é poderoso instrumento de dominação, nem mesmo como condição necessária da tecnocracia. Ela é poderoso instrumento de dominação porque é fonte de intimidação.

[...] Interpostos entre nós e nossas experiências, esses discursos competentes tem a finalidade de fazer-me considerar minha própria vida como desprovida de sentido enquanto não for obediente aos cânones do "progresso cientifico" que me dirá como ver, tocar, sentir, falar, ouvir, escrever, ler, pensar, viver.

Afinada à essa leitura crítica do conhecimento científico, a concepção de educação permanente que nos orienta resgata autores analisados por Ferreira (2015), sobretudo, a formulação de Dewey (1979) e Freire $(1988 ; 2000)$ acerca da importância da educação para a vida democrática, uma vez que só ela é capaz de desenvolver o pensamento reflexivo sobre os problemas da experiência social. Para Dewey há pelo menos três formas de articular democracia e educação: pelo reconhecimento de que todos sujeitos produzem cultura e 
conhecimento; pelo acesso à produção cultural e de conhecimento; pela desnaturalização da hierarquia entre ciências "puras" e ciências "aplicadas".

Os processos de educação permanente na política pública de Assistência Social precisam guardar coerência com o princípio de participação social inscrito na Lei Orgânica de Assistência Social. Daí a necessidade de explicitarmos, nessa seção, algumas referências que contribuem para fundamentar o nexo entre processos de educação em serviço e a democratização da política pública de Assistência Social.

Ao fundamentar a pedagogia da problematização como referência para os processos de educação permanente do SUAS, Ferreira $(2015$, p. 35,95$)$ assim define:

\begin{abstract}
As práticas concretas, histórica e culturalmente situadas são a matériaprima dos processos de educação permanente baseados na pedagogia da problematização. Quando questionadas e postas em análise, produzem situações problemáticas que são a primeira produção coletiva num processo de aprendizado institucional.

[...] As situações problemáticas devem ser exploradas em dois níveis: o da implicação e o da explicação. O primeiro remete à experiência concreta dos trabalhadores e suas formas de enunciar a própria experiência. $O$ segundo nível - da explicação - remete a diferentes recursos teóricos e analíticos aos quais se pode recorrer e mobilizar nos processos de educação permanente.
\end{abstract}

A participação dos cidadãos usuários, embora declarada como direito e prevista como diretriz da política pública de Assistência Social, se mantém como força instituinte. 0 projeto político do SUAS, ao advogar a responsabilização do Estado pela proteção social devida aos cidadãos, demarca com nitidez a oposição em relação à matriz tutelar e assistencialista que reproduz a lógica de submissão dos "pobres" e "carentes" pela identificação de ausência materiais com carências morais. Em seu lugar, o SUAS reconhece os cidadãos como sujeitos de direitos, capazes de vocalizar por si próprios seus interesses, desejos e projetos coletivos.

A experiência profissional sistematizada nesse artigo transporta a diretriz da participação para o ambiente educativo em que os trabalhadores são sujeitos ativos num processo de aprendizagem dialógica. Nesse ambiente, a criação de materiais instrucionais que apoiem os trabalhadores no enfrentamento de seus desafios cotidianos está baseada numa concepção de instituição em que suas dimensões instituintes sejam reconhecidas. 
Sendo a educação permanente uma ferramenta de gestão do trabalho no SUAS ${ }^{1}$ que visa disparar reflexões e mudanças nos processos de trabalho, é necessário explicitar o conceito de instituição que orienta nossa reflexão:

[...] A instituição, embora se apresente como um fator exterior ao homem, necessitou de seu poder instituinte. Além disso, se o homem sofre as instituições, também as cria e mantém por meio de um consenso que não é somente passividade diante do instituído, mas igualmente atividade instituinte a qual, além disso, pode servir para pôr em questão as instituições. O fato de que uma instituição seja contestada também faz parte dela. (LOURAU, 1977, p. 73)

Nos processos de educação permanente que desenvolvemos, a participação social no SUAS tem sido problematizada pelas equipes profissionais e também, embora ainda raro, pelos próprios usuários. Insatisfações quanto ao não reconhecimento público das vozes de usuários, desejos de mudança nos processos de trabalho para gerar maior presença nas atividades ofertadas nos serviços, constatações da baixa ou inexistente representação dos usuários nos conselhos e conferências de Assistência Social são algumas das manifestações do grau de implicação de trabalhadores, gestores e conselheiros.

Elaboramos esse artigo com o objetivo de disponibilizar um texto-ferramenta que estimule trabalhadores do SUAS - e quiçá de outras políticas públicas - a refletir sobre suas práticas cotidianas e o quanto suas escolhas profissionais têm materializado a diretriz da participação social.

Ao sistematizar para aprender com nossa experiência - compartilhada com muitas equipes da gestão e dos serviços socioassistenciais - afirmamos que processos de educação permanente não são mera transmissão de conteúdos. Processos de educação permanente são, essencialmente, oportunidades para desenvolver o pensamento reflexivo sobre problemas reais que marcam nossa experiência no enfrentamento das desigualdades sociais. Desse modo, educação permanente é também o tempo e o espaço comum para produzirmos conhecimentos que ampliem modos de viver nossa ainda frágil democracia.

\footnotetext{
${ }^{1}$ A Política Nacional de Educação Permanente do SUAS, aprovada pela Resolução do Conselho Nacional de Assistência Social (CNAS, Resolução n.4, de 2013), é o instrumento que define diretrizes e responsabilidades dos entes federados acerca dos processos de formação e capacitação das equipes de referência do SUAS.
} 


\section{Participação Social no Brasil}

A intensificação dos debates e estudos sobre a participação social nas políticas públicas se expressa a partir da Constituição Federal de 1988. A partir desse marco legal, as políticas sociais no Brasil passaram a ter como diretriz a participação social e a descentralização política e administrativa. A perspectiva que orienta e fundamenta tal modelo é a de que quanto maior a participação de diferentes atores da sociedade civil nas decisões das políticas públicas mais estas responderão aos interesses coletivos, o que, por consequência, induz a superação da tradicional forma de exercício do poder governamental brasileiro, fortemente centralizado, meritocrático e vinculado às práticas clientelistas e patrimonialistas.

Os novos valores que se colocam em cena, a partir de então, pressionam agentes públicos, ao mesmo tempo em que incentivam grupos sociais para a adoção de novas práticas no processo de construção das decisões governamentais, de modo a inserir indivíduos e coletivos que dantes não tinham acesso e informação sobre essas decisões. Pressupõe-se, então, que essas decisões sejam tomadas a partir de um amplo conhecimento por parte das pessoas diretamente impactadas por elas. O cidadão e a cidadão deveriam então conhecer qual é a motivação para adotar determinadas decisões e, principalmente, ter oportunidade para vocalizar seus interesses, que ao serem considerados, possam redefinir prioridades ou mesmo as formas de executar as decisões tomadas.

Assim, previu-se na Constituição de 1988 a criação de instâncias de deliberação na gestão das políticas sociais públicas - com denominação de conselhos-, órgãos colegiados de composição paritária entre governo e sociedade civil, cuja composição prevê na maior parte dos "arranjos": representação de usuários, prestadores de serviços e trabalhadores. O princípio de participação que inspirou a criação dos conselhos das políticas sociais partiu da crítica quanto à insuficiência dos mecanismos de representação, especialmente via poder legislativo, para garantir o exercício da democracia e os interesses dos cidadãos. Além dos conselhos, outros dispositivos de democracia direta e participativa foram reconhecidos, tais como referendo, plebiscito e iniciativa popular como forma de garantir maior participação de setores da sociedade civil na gestão pública (BENEVIDES, 1998).

Após quase três décadas de práticas conselhistas e de conferências em diferentes políticas públicas no Brasil, o debate sobre participação avançou para reflexões sobre o 
reconhecimento da importância dessas instâncias. Ao mesmo tempo, muitos analistas avaliam a insuficiência desses mecanismos para assegurar políticas sociais efetivamente democráticas e participativas (AVRITZER, 2012; AVRITZER; SANTOS, 2013; CUNHA, 2009; SOUZA, 2011). Apontam esses estudos, a relevância de que sejam associadas à atuação em conselhos, ações de participação direta que envolvam amplos segmentos da sociedade. (TATAGIBA, 2002, p. 100)

Uma breve recuperação sobre os limites da participação e do controle social via conselhos justifica, e exige, o alargamento do debate da participação para além dessas instâncias. Muitas análises ${ }^{2}$ apontam desafios para os conselhos deliberativos como, por exemplo, a necessidade de equilíbrio no processo decisório o que seria assegurado pela paridade entre governo e sociedade civil. Observa-se, entretanto, que a paridade numérica não assegura paridade política, visto que o acesso às informações e a capacidade de intervenção é bastante distinta entre conselheiros, o que exige processos formativos continuados que ainda não são realidade em todo o território nacional. (COTTA et al., 2006, p. 432).

Cabe aqui uma rápida ponderação sobre a ideia de paridade política para assegurar decisões mais democráticas em conselhos. O debate no interior de conselhos se estabelece ainda numa linguagem predominantemente técnica, o que por vezes exclui a representação de usuários e até mesmo de alguns trabalhadores, por exigir um domínio de dialetos institucionais e mesmo de formas de tramitação burocrática que não são conhecidas pelo coletivo de representantes. Poder-se-ia afirmar que há uma distância entre os rituais estabelecidos no âmbito do controle social, que se expressa também na linguagem usual, e o cotidiano da atenção em políticas públicas, distância essa que se intensifica ainda mais ao considerarmos o cotidiano vivido por cidadãos e cidadãs demandantes da atenção pública.

As exigências colocadas pelos rituais de controle social, demandam um certo padrão de representação, um domínio de códigos que não são de apropriação coletiva e que, por vezes, distanciam representantes dos debates e embates presentes na execução das políticas públicas. Ante esse cenário, é necessária uma reflexão sobre escolhas políticas que definem não só a pauta, mas também o modo de funcionamento de conselhos, para que

\footnotetext{
2 Referimo-nos aqui especialmente às produções de Tatagiba (2002); Cunha (2009), e estudos do IPEA (2012; 2013), organizados por Leonardo Avritzer que vêm também analisando o impacto das Conferências Nacionais para fortalecer participação e controle social de políticas públicas.
} 
não se tornem mecanismo de legitimação de formas tecnicistas e centralizadoras de gestão de políticas públicas. Seria o caso de nos indagarmos o que é imprescindível para o controle social de uma política pública, definido esse consenso, essas informações e conhecimentos deveriam estar à disposição de todos as pessoas que têm interesse nessa área, seja por demandarem sua atenção, seja por trabalharem nesse campo ou seja tão somente porque desejam monitorar o funcionamento do poder público. Procedimento que de fato não acontece, não somente na Assistência Social, mas também nesse campo.

O debate sobre o processo decisório em condições de paridade política, exige repensar também as condições de representação da sociedade civil como um todo e do segmento de usuários e usuárias em particular. São fartos os estudos que apontam uma precária representação de usuários e usuárias que se dá não só numérica, mas também qualitativamente, se comparada, por exemplo, com a representação de organizações prestadoras de serviço. Em estudo recente, Cunha destaca que vários estudos sobre o perfil de conselheiros de assistência social e saúde, demonstram que essas pessoas possuem escolaridade e renda acima da média da população, como também apontam "que há desigualdades na sua capacidade de deliberação associada às desigualdades sociais, especialmente os usuários da política, com variação importante conforme a área de política pública" (CUNHA, 2013, p. 149).

Esses aspectos específicos de conselhos, associados a outros elementos próprios de instâncias de representação, vão sinalizando a insuficiência de conselhos para assegurar a participação em todo o ciclo de políticas públicas. Tal constatação, abriu espaço para um debate mais intenso sobre a necessidade de considerar a participação como conteúdo e objetivo do próprio trabalho social nos serviços públicos (RAICHELIS, 2009; RIZZOTI, 2011). Assim, a participação nos serviços são é somente uma 'educação para a cidadania', mas acima de tudo a vivência da cidadania em ato, materializada em metodologias participativas do trabalho social, que pautadas no reconhecimento da produção coletiva de subalternidade resultariam na valorização do direito de cidadãos e cidadãs a acessarem serviços públicos criados para combater os efeitos e enfrentar as causas de violências e violações coletivas.

O que se advoga aqui é que para intensificar o controle social e para que o Sistema Único de Assistência Social se constitua de fato em um Sistema participativo e democrático, os mecanismos instituídos de controle social (conselhos, conferências, audiências públicas), em que pese sua relevância, são insuficientes, é fundamental associar aos espaços de 
representação formas de assegurar vivências participativas no cotidiano do funcionamento dessa política pública, o que exige repensar os modos de fazer gestão e de produzir relações de atenção direta a usuários e usuárias de serviços.

Ressalte-se que não estamos abordando a intensificação da participação no cotidiano da política pública em exclusão ou substituição aos espaços instituídos de controle social, ao contrário, trata-se de afirmar a maior eficiência e força política desses espaços se associa diretamente à intensificação da participação de diferentes atores e segmentos nos modos de fazer a gestão e produzir atenções nessa política pública.

$\mathrm{Na}$ assistência social esse debate se intensifica com a aprovação da Política Nacional, em 2004, e ganha força com a deliberação na Conferência Nacional, em 2005, dos dez direitos socioassistenciais de usuários e usuárias. Nesse decálogo, os direitos 3ㅇ e 10은 explicitam o acesso à informação, o protagonismo e o controle social como direito de todo e qualquer cidadão e cidadã atendido na assistência social.

De seu lado, a Tipificação Nacional de Serviços Socioassistenciais, aprovada em resolução do CNAS, em 2009, padroniza os serviços e explicita aquisições de proteção esperadas na assistência social. As aquisições de autonomia dos usuários preveem, entre outras: ter acesso a atividades, segundo suas necessidades, interesses e possibilidades; ser informado e orientado sobre direitos e como acessá-los; ser ouvido para expressar necessidades, interesses e possibilidades; ter respeitados os seus direitos de opinião e decisão; ter acompanhamento que possibilite o desenvolvimento de habilidades de autogestão, auto sustentação e independência e por fim, afirma a tipificação, que a avaliação do serviço se constitui como um ganho de autonomia para usuários e usuárias.

Nessa mesma perspectiva, Torres (2013), aponta que só é possível a uma pessoa reconhecer-se como cidadão ou cidadã, a partir dos modos de tratamento e das relações estabelecidas no interior dos serviços públicos. Assim, é fundamental a vivência de oportunidades de participar, autonomamente, das decisões que the diz respeito, o que exige assegurar, como previsto no 3ㅇ direito socioassistencial: [o direito de] "manifestar-se, exercer protagonismo e controle social na política de assistência social, sem sofrer discriminações, restrições ou atitudes vexatórias derivadas do nível pessoal de instrução formal, etnia, raça, cultura, credo, idade, gênero, limitações pessoais".

Estabelece-se assim uma clara relação entre a vivência concreta de participação pelos usuários e usuárias como decorrente dos processos de trabalho social. De modo que, 
nessa concepção a participação é, ao mesmo tempo, uma diretriz para o trabalho no âmbito do SUAS, constitui-se no método de realizar a intervenção e, por fim, é o resultado esperado do trabalho, uma vez que compõe o campo de aquisições de usuários e usuárias na atenção em serviços. Desenvolver o trabalho social nessa perspectiva, pressupõe o estabelecimento de uma forma específica de relação entre trabalhadores/as e usuários/as que se constitui numa aliança (RIZZOTI, 2011). Esse modo de relação, oferta para usuárias/os a vivência de uma experiência de valorização e reconhecimento que se contrapõe à produção social da subalternidade e permite o reposicionamento na relação com os serviços públicos e com os espaços sociais coletivos, ampliando sua autonomia e protagonismo, ou seja, Ihes assegurando a vivência de ser sujeito de direitos.

Trabalhar na perspectiva do fortalecimento da autonomia é corresponsabilizar-se pelas escolhas e decisões que os indivíduos vivenciam ao longo de suas trajetórias e fomentá-las na atuação profissional no âmbito da política pública. É também fortalecer a participação das pessoas em processos decisórios, sejam eles vinculados à sua própria vida, como também aos serviços em que são atendidos. (TORRES, 2013, p. 234)

Ao tratar da participação cidadão em serviços socioassistenciais, Berenice Couto (2014) reafirma a conclusão que chegou quando da elaboração de sua tese de doutorado. Para ela, só é possível a assistência social ser um direito social com a participação popular. Argumenta que a assistência social lida com uma população que tem sua trajetória fortemente marcada pela subalternidade, vista como pessoas que "não sabem o que querem" e que, por isso mesmo, é necessário que alguém pense e faça por eles.

Ressalta que só se aprende a ser sujeito político participando. Essa direção impacta diretamente nas práticas profissionais na assistência social que para ela está eivada de "nomes grandiosos" convivendo com cotidianos burocráticos, repetitivos e impregnados de subalternização.

Para fortalecer a participação e o protagonismo do cidadão no cotidiano dos serviços socioassistenciais, Couto (2014) aponta que essa participação não pode ser tomada como um recurso gerencial ${ }^{3}$ que serve para legitimar decisões que visam economizar

\footnotetext{
3 Para NOGUEIRA (2004), quando a participação é tomada como um recurso gerencial, as pessoas podem participar sem se intrometer significativamente no estabelecimento das escolhas essenciais. Podem permanecer subalternas a deliberações técnicas ou a cálculos políticos engendrados nos bastidores, em nome da necessidade que se teria de obter suportes técnico-científicos para decidir ou de concentrar certas decisões eminentemente políticas. (NOGUEIRA,2004, p. 143)
} 
recursos, organizar o trabalho e definir procedimentos burocráticos. Ao contrário, o fomento ao protagonismo dos sujeitos precisa deslocar modos de fazer, ao descrever essas mudanças necessárias a autora faz alguns destaques, que destacamos a seguir:

O primeiro destaque diz respeito a uma necessária ruptura na relação estabelecida entre profissionais e usuárias/os que é marcada pela cultura de produção de subalternidade. Esse modo de atuação, se alimenta da lógica seletiva que define que a atenção dos serviços deve voltar-se àqueles que vivem em situação de pobreza absoluta. Assim, se é para atender prioritariamente ou exclusivamente essas situações, aprimora-se cada vez mais critérios extremamente seletivos, que buscam averiguar quem realmente necessita, ao definir quem são essas pessoas, a atenção termina por ser controladora, investigativa das narrativas apresentadas e redutora do status de cidadania desses sujeitos. Ora, tal direção confronta em absoluto com a lógica dos direitos que pressupõe que o Estado tem obrigações e o cidadão tem direito, o que para a autora "representou uma verdadeira revolução do ponto de vista conceitual da forma como a Assistência Social vinha sendo trabalhada no Brasil." (COUTO, 2014, p. 391)

A restrição e seletividade no acesso aos serviços gera, por consequência, uma leitura de que o trabalho desenvolvido é mais do suficiente ou necessário, porque "para quem não tem nada qualquer coisa que é ofertada já está muito bom, se não tivesse isso, seria bem pior". Nessa linha de relação de causalidade, poder-se-ia dizer também que não há do que reclamar, usuários têm mais é que agradecer a atenção recebida. Não há, nesse modo de conceber e realizar o trabalho, nenhum compromisso com a qualidade da atenção, com as necessidades dos sujeitos e tampouco com a universalização do acesso, o ponto de partida é sempre aquilo que o serviço pode oferecer e não o que o sujeito necessita receber como proteção.

Agrega-se a essa direção a ideia de justificar o não atendimento, indicando que as pessoas voltem outro dia, ou ainda agendando-as indefinidamente. Afirma a autora que a ausência de recursos deve ser comunicada à população, como também ela deve partilhar das informações que o diagnóstico socioterritorial levantou, pois tais informações podem ser instrumento de mobilização e de discussão para a população atendida. Lembra que as mudanças em políticas públicas decorrem de pressão popular, assim propõe que mais informações sobre as lacunas de atenção podem oportunizar maior posicionamento em defesa dessa política pública. 
Outro aspecto a ser destacado dessa reflexão, diz respeito à produção de sujeitos protagonistas. Indaga: "como se aprende a ser sujeito político" e responde: "Só há uma forma: aprende-se a ser sujeito político participando". A questão central em debate referese ao reconhecimento de que as práticas que fortalecem sujeitos não são obviamente as que produzem subalternidade.

Assim, em perspectiva similar à apontada por Rizotti (2011) destaca Berenice Couto uma necessária aliança entre os trabalhadores que atuam nos serviços e os sujeitos neles atendidos, reconhecer-se como classe trabalhadora, para a autora, é uma dimensão política essencial nessa relação. Além disso, é fundamental lidar com demandas reconhecendo-as como expressão da superexploração a que está submetida a classe trabalhadora, portanto não são questões de natureza individual e tampouco serão superadas a partir de medidas simplistas, como arrumar a casinha, conseguir emprego, vestir-se melhor. Afirma que os profissionais não podem ter uma visão ingênua e desinformada da realidade dos territórios em que atuam e das relações neles estabelecidas por quem ali vive, como também não podem desrespeitar os cidadãos de direitos ao ignorar suas trajetórias e modo de vida.

[Trata-se] de trabalhar a partir daquilo que o dialético conhecimento da realidade proporciona a respeito daquela população. Ouvi-la, ouvir o que diz, pois a população sobrevive em situações tão adversas que nenhum trabalhador social é capaz de supor. Sem ouvir e pensar junto, de fato, pode-se até apresentar a melhor intenção, mas será vazia de potencial transformador. (COUTO, 2014, p. 397)

\section{Gradações da Participação como Analisadores de Processos de Trabalho no SUAS}

Partimos da premissa de que os resultados esperados do trabalho social são alcançados gradativamente, uma vez que ele se dá em contextos sociais complexos, mobilizando, simultaneamente, interesses e ações de diferentes atores e instituições. Em decorrência, é necessário construir instrumentos para conhecer alcances parciais do trabalho social e dispor de estratégias institucionais capazes de sinalizar sua ampliação e aprimoramento. Por isso, entendemos que a educação permanente é uma estratégia institucional de gestão do trabalho na assistência social que cria espaços para uma atitude reflexiva dos trabalhadores, promove a apropriação de conhecimentos já existentes e provoca a produção de novos conhecimentos e saberes. 
Em nossa experiência em processos de educação permanente temos, de um lado, reiterado e disseminado concepções já pactuadas coletivamente sobre o que é participação: desde o reconhecimento de sua previsão como direito constitucional até sua acepção no conjunto de normas e orientações do SUAS; de outro lado, temos colocado à disposição dos trabalhadores estudos e pesquisas sobre diferentes temáticas, entre as quais a participação e o controle social. E para que o processo de aprendizagem aconteça de forma ativa e reflexiva, produzimos materiais instrucionais que facilitem a articulação entre o já sabido e os novos saberes a serem construídos.

Os gradientes de partipação que descreveremos a seguir são parâmetros simples e inteligíveis, produzidos a partir das elaborações de Bobbio (1998) e Nogueira (2004). Com eles buscamos estimular a reflexão dos trabalhadores sobre o quão próximo ou distante o trabalho social está em relação à concepção da participação como 'situações coletivas em que o cidadão contribui direta ou indiretamente para uma decisão política'. Nesse sentido de gradualidade, a definição de Muñoz (2004, p. 57) é bastante oportuna:

Participação não se improvisa e não se aprende de imediato, requer reconhecer que não se está no lugar do outro, mas que é possível fazer perguntas inteligentes e respeitosas que permitam que o outro expresse suas características, o que e como pensa, o que e como sente e deseja.

Desse modo, os gradientes podem ser apropriados como instrumento de planejamento do trabalho social com vistas a estimular o incremento de graus cada vez mais amplos de interferência dos usuários nas decisões políticas que afetam suas vidas e de sua coletividade. A variação ascendente dos seis gradientes vai da participação menos intensa nos processos de decisão até maior grau, que corresponde à interferência na tomada de decisões.

\section{Gradientes de Participação}

O primeiro gradiente é estar presente, entendido como sinônimo de comparecimento e frequência ao serviço. Estabelece para o serviço a tomada de decisão quanto ao horário e local onde o trabalho social é desenvolvido, podendo ser mais ou menos condizentes com as reais possibilidades de acesso dos cidadãos. 
'Estar presente' pode representar o reconhecimento que os usuários têm do trabalho desenvolvido ou que os serviços são, potencialmente, capazes de acolher e dar resolutividade aos sofrimentos individuais e coletivos por eles vividos. Por isso, requer criar condições para que os cidadãos sejam escutados e se sintam acolhidos por meio de atitutes e posturas dos profissionais que demonstrem que sua presença é esperada ali.

Embora já expresse um grau de participação, trata-se da forma menos intensa, especialmente quando presença do usuário se dá na condição de ouvinte. Se o trabalho social é baseado intervenções prescritivas para orientar como as pessoas devem viver, a presença nos serviços não configura indicador de participação, pois expressa um lugar passivo e de submissão ao "discurso competente" do profissional. Nessa circunstância, tem como efeito nos usuários a reprodução da sensação de culpa e desproteção diante das situações de vulnerabilidade em que vive.

O segundo gradiente é 'manifestar opinião', entendido como a expressão espontânea e voluntária dos usuários nas situações cotidianas dos serviços. Expressa também um grau incipiente de participação pois, de um lado, o espontaneísmo pode indicar ausência de estratégias mais estruturadas do trabalho social para que os usuários expressem suas opiniões. De outro lado, é um grau de participação acima do anterior, pois a proatividade dos usuários pode indicar um senso de autorespeito e altivez e, com isso, ser capaz de induzir a criação de condições para a livre manifestação nos serviços. Como efeito, pode produzir maior confiança para expressar o que querem, pensam e sentem sem ameaças, críticas ou julgamento de valor nos serviços.

O terceiro gradiente é 'ser consultado'. Incremento de participação em relação ao anterior, expressa uma situação de diálogo entre alguém interessado na opinião de outrem; é um ato que, em si, institui uma relevância e importância para o interlocutor. Diz respeito à presença de estratégias estruturadas do trabalho social para valorizar e estimular nos usuários a expressão de seus interesses, desejos e opiniões.

No processo democrático a consulta associa-se à perspectiva de que a opinião emitida poderá ser levada em consideração na tomada de decisões, podendo acarretar mudanças para os usuários e sua coletividade. Essa vivência produz maior simetria de poder entre profissionais e usuários nos serviços, sobretudo para esses sujeitos cujas vivências são fortemente marcadas pela condição de subalternidade e humilhações. 
Quando a consulta é utilizada apenas para forjar a participação em processos cuja decisão já tenha sido tomada (e não dita) de antemão, ela não pode ser considerada um incremento de participação.

O quarto gradiente é 'estar informado' é uma condição bastante consensual nos debates sobre participação, pois não é possível participar sem ter acesso às informações relevantes. Pressupõe que os serviços criem condições para acesso e circulação de informações entre aqueles que tem acesso ou produzem informações e conhecimentos que impactam a vida dos usuários e da coletividade em que vivem.

Estar informado não significa transmissão unilateral de informações, mas a troca de conhecimentos que pressupõe a valorização de saberes diferentes e igualmente importantes para a leitura da realidade. Por isso, representa um grau muito mais intenso de participação.

De um lado, trata-se de uma mudança significativa da cultura institucional dos serviços públicos que, via de regra, funcionam segundo a lógica de um saber-poder concentrado e obscurecido por discursos tecnicistas. Quando informados com clareza e em linguagem adequada, os usuários sentem-se esclarecidos sobre processos, acontecimentos e decisões para formular seus próprios juízos de valor e, assim, são capazes de dimensionar as consequências que eles têm para si e para a coletividade 4 .

De outro lado, a participação efetiva-se também quando as informações e conhecimentos dos usuários sobre a realidade em que vivem - em sua família, nos serviços públicos e nos territórios de vivência - são reconhecidos como relevantes para a tomada de decisão nos serviços ${ }^{5}$.

O quinto gradiente é 'estar mobilizado' e expressa uma das consequências políticas da realização do grau de participação anterior, pois diz respeito à condição na qual os usuários estão interessados na coisa pública, ativos, estimulando e organizando outros para interferir nas decisões de interesse comum. Indica um grau aprimorado do trabalho social, pois pressupõe a existência e sustentação de estratégias coletivas nos serviços - campanhas, articulação com movimentos sociais, debates ampliados, audiências públicas - que

\footnotetext{
${ }^{4}$ Informações sobre as responsabilidades dos serviços da assistência social, sobre os demais direitos de cidadania e sobre os processos sociais que produzem as desigualdades às quais estão submetidos são alguns conhecimentos que precisam ser compartilhados e trocados entre profissionais e usuários.

${ }^{5}$ Essa presença [dos "sujeitos falantes"] desestabiliza consensos estabelecidos e permite alargar o "mundo comum", fazendo circular na cena pública outras referências, outros valores, outras realidades, que antes ficavam ocultados ou então eram considerados irrelevantes, desimportantes para a vida em sociedade. (TELLES, 2003, p.69).
} 
constroem identidades coletivas nas quais os usuários podem reconhecer problemas comuns e poder político para enfrenta-los por meio da mobilização.

Estar mobilizado é estar em movimento, é ser capaz de dialogar com outras pessoas, influencia-las e permitir-se ser influenciado por elas por meio da expressão de interesses e formulação de propostas.

Por representar um alto grau de participação, a mobilização pode ampliar a participação de outros usuários no âmbito dos serviços, a exemplo de comissões e conselhos gestores; pode também extrapolar os limites dos serviços e alçar movimentos em nível territorial e municipal, a exemplo das conferências e do próprio conselho. Em quaisquer dessas escalas 'estar mobilizado' impacta a visão de mundo dos usuários, seus modos de compreender as situações em que vivem e propor soluções mais coletivas e justas. Entretanto, é preciso reconhecer que os processos de mobilização são custosos para as pessoas, tanto do ponto de vista material como emocional. Estar mobilizado exige certo nível de exposição pessoal, envolve dispor da própria credibilidade para estimular que outros se coloquem em movimento. Por isso, nos processos de mobilização é fundamental estabelecer momentos de avaliação e análises que reflitam se as mudanças esperadas foram alcançadas e quais ainda demandam mobilização e reflexão coletiva.

O sexto e ultimo gradiente é 'influenciar decisões' e afirma que a melhor expressão da autonomia e protagonismo dos sujeitos é a capacidade de tomar decisões. Por isso, tratase do mais alto grau de participação a ser construído no trabalho social nos serviços e que só é alcançado na processualidade dos demais gradientes anteriores. Essa autonomia é produzida por meio de vivências gradativas e constantes que partem de questões mais imediatas e singulares, até as mais gerais e coletivas. Ou seja, demanda planejamento, tempo e sustentação de estratégias participativas nos serviços.

A capacidade de influenciar decisões de grupos e pessoas na perspectiva democrática opera por meio de argumentos e explicações; nunca por discursos de autoridade ou manipulações. Assim, é preciso que os serviços assegurem as condições para que os usuários expressem, ao seu modo, os motivos que justificam porque uma escolha é melhor que outra, seja para sua própria vida, seja para a coletividade a qual pertence.

A autonomia, como apontado anteriormente, é uma aquisição esperada do trabalho social nos serviços da assistência social. Entendemos que esse nível de participação será possível tanto mais os serviços produzam oportunidades de compreender as situações 
vividas, argumentar sobre a visão existente sobre elas e sobre as melhores escolhas para produzir mudanças que representem ganhos de cidadania, o que, por consequência, exige a capacidade dos serviços públicos produzirem oportunidades para a vivência dessas escolhas na relação entre sujeitos sociais e Estado.

\section{Considerações Finais}

Conforme apontado, os gradientes de participação aqui sistematizados foram cosntruídos como material instrucional que temos utilizado nos processos de educação permanente que realizamos com equipes que atuam nos serviços socioassistencias, tanto na proteção social básica quanto especial. Nessas experiências, que têm se dado em diferentes municípios, temos buscado estimular a criação de situações cotidianas que sejam dirigidas, intencionalmente, para criar oportunidades de participação que se concretizam na manifestação da opinião, na circulação de informações e, principalmente, na oportunidade de tomar decisões a partir de situações propostas pelos serviços. Nossa aposta política é que uma escuta intencional que, genuinamente, se interessa pela opinião e narrativa dos usuários, reconhece e valoriza o que eles pensam, sentem e desejam.

No diálogo com os profissionais participantes desses processos há várias manifestações apontam a importância desses gradientes como apoio e referencia para avaliarem o grau de participação que tem sido alcançado nos serviços nos quais atuam. Nese sentido, têm sido utilizados tambpem planejar ações que visam ampliar e fortalecer a participação nos serviços. Destacam ainda a objetivação que os gradientes representam quando adotados como parâmetros para o trabalho, pois favorecem a criação de estratégias distintas, em conformidade com o grau de participação proposto em cada um deles.

De outro lado, no próprio processo de educação permanente adotamos os gradientes para estimular que os profissionais desenvolvam sua aprendizagem por meio de vivências que permitam que manifestem livremente sua opinião e que possam experimentar momentos de tomada de decisão por meio de argumentos construídos no diálogo e a partir de informações e conhecimentos disponibilizados nos processos de capacitação. Nossa aposta é que a experiência de participação oferece uma aprendizagem singular por meio da qual os profissionais sentem-se mais aptos e motivados para rever suas intervenções e adotar práticas mais horizontais e fortalecedoras da autonomia dos sujeitos nos serviços. 
Desse modo, o uso dos gradientes de participação se constitui em uma experiência em curso, mas que tem se mostrado para nós bastante promissora na reflexão e revisão do trabalho social no cotidiano dos serviços.

\section{Referências}

AVRITZER, L. Conferências nacionais: ampliando e redefinindo os padrões de participação social no Brasil. Brasília: IPEA, 2012. (Texto para Discussão 1739).

AVRITZER, L.; SOUZA, C. H. L. (Org.) Conferências nacionais: atores, dinâmicas participativas e efetividades. Brasília: Ipea, 2013.

BENEVIDES, M. V. M. A cidadania ativa: referendo, plebiscito e iniciativa popular. 3. ed. São Paulo: Ática, 1998.

BOBBIO, N. et. al. Dicionário de Política. 11. Ed. Brasília: UNB, 1998.

COTTA, R. M. M.; CAZAL, M. M.; RODRIGUES, J. F. C. Participação, controle social e exercício da cidadania: a (des)informação como obstáculo à atuação dos conselheiros de saúde. Physis, 2009.

CUNHA, E. S. M. Conferências de Políticas Públicas e Inclusão Participativa. In: AVRITZER, L.; SOUZA, C. H. L. (Org.). Conferências nacionais: atores, dinâmicas participativas e efetividades. Brasília: Ipea, 2013.

Efetividade deliberativa: estudo comparado de conselhos municipais de assistência social. 2009. Tese (Doutorado) - Universidade Federal de Minas Gerais, Belo Horizonte, 2009.

CHAUÍ, M. Cultura e democracia. Crítica y emancipación: Revista latinoamericana de Ciencias Sociales, Buenos Aires, Año 1, n. 1, Jun. 2008..

COUTO, B. R. Protagonismo popular, subalternidade e direito ao trabalho: consensos e dissensos no debate da assistência social. In: PAIVA, B. A. (Org.). Sistema Único de Assistência Social em perspectiva: direitos, política pública e superexploração. São Paulo: Veras, 2014.

DEWEY, J. Democracia e educação. Tradução de Godofredo Rangel e Anísio Teixeira. São Paulo: Nacional, 1979. (Atualidades Pedagógicas, v. 21)

FERREIRA, S S. Educação Permanente no Sistema Único de Assistência Social: gestão democrática para uma ética pública. 2015. Tese (Doutorado) -Pontifícia Universidade Católica de São Paulo, São Paulo, 2015.

FREIRE, P. Pedagogia da autonomia: saberes necessários à prática educativa. São Paulo: Paz e Terra. 15. ed. 2000. 
Pedagogia e mudança. Rio de Janeiro: Paz e Terra, 1988.

LOURAU, R. Objeto e método da Análise Institucional (1977). In: ALTOÉ, S. René Lourau. Analista Institucional em tempo integral. São Paulo: Hucitec, 2004.

MERHY, E. O desafio que a educação permanente tem em si: a pedagogia da implicação. Interface - Comunicação, Saúde, Educação. Botucatu, v.9, n. 16, 2005.

MUNOZ, C. Pedagogia da Vida Cotidiana e participação cidadã. São Paulo: Cortez, 2004.

NOGUEIRA, M. A. Um estado para a sociedade civil: temas éticos e políticos da gestão democrática. São Paulo: Cortez, 2004.

RAICHELIS, R. A trajetória e o significado do controle social na política de assistência social: a diretriz constitucional em debate. In: BRASIL. Ministério do Desenvolvimento Social. Caderno de textos: participação e controle social no SUAS. Brasília: CNAS/MDS, 2009.

RIZZOTTI, M. L. A. A Aliança estratégica entre os trabalhadores e os usuários do SUAS. In: BRASIL. Ministério do Desenvolvimento Social e Combate à Fome. Gestão do trabalho no âmbito do SUAS: uma contribuição necessária. Brasília, DF: Secretaria Nacional de Assistência Social, Ed. Brasil, 2011.

TATAGIBA, L. Os Conselhos Gestores e a Democratização das Políticas Públicas no Brasil. In: DAGNINO, E. (Org.). Sociedade Civil e Espaços Públicos no Brasil. São Paulo: Paz e Terra, 2002.

TELLES, V. S. Direitos Sociais: afinal do que se trata? In: Muitos lugares para aprender. São Paulo: CENPEC/Fundação Itau Social/Unicef, 2003.

TORRES, A. S. Segurança de convívio e de convivência: direito de proteção na Assistência Social. 2013. Tese (Doutorado) - Pontifícia Universidade Católica de São Paulo, São Paulo, 2013. 